GRASAS Y ACEITES 70 (1)

January-March 2019, e295

ISSN-L: 0017-3495

https://doi.org/10.3989/gya.0570181

\title{
Stability and volatile oxidation compounds of grape seed, flax seed and black cumin seed cold-pressed oils as affected by thermal oxidation
}

\author{
M. Kiralan ${ }^{\mathrm{a}}$, G. Çalik ${ }^{\mathrm{b}}$, S. Kiralan ${ }^{\mathrm{a}}$, A. Özaydin ${ }^{\mathrm{c}}$, G. Özkan ${ }^{\mathrm{d}}$ and M.F. Ramadan ${ }^{\mathrm{e}, \mathrm{f}, 凶}$ \\ ${ }^{a}$ Department of Food Engineering, Faculty of Engineering, University of Balikesir, Balikesir, Turkey \\ ${ }^{b}$ Faculty of Engineering and Architecture, Department of Food Engineering, Abant Izzet Baysal University, Bolu, Turkey. \\ ${ }^{\mathrm{c} S u l e y m a n}$ Demirel University, Experimental and Observational Student Research and Practice Center, Isparta Turkey. \\ ${ }^{\mathrm{d}}$ Faculty of Engineering, Department of Food Engineering, Suleyman Demirel University, Isparta, Turkey. \\ ${ }^{\mathrm{e}}$ Faculty of Agriculture, Biochemistry Department, Zagazig University, Zagazig 44519, Egypt \\ ${ }^{\mathrm{f}}$ Deanship of Scientific Research, Umm Al-Qura University, Makkah, Kingdom of Saudi Arabia. \\ ${ }^{\square}$ Corresponding author: hassanienmohamed@yahoo.com
}

Submitted: 05 May 2018; Accepted: 04 September 2018

\begin{abstract}
SUMMARY: The old-pressed oils (CPO) from grape seeds (GSO), flax seeds (FSO) and black cumin seeds (BSO) were analyzed for their fatty acid profiles, tocopherols, total phenolics, bioactives and phenolic compositions. The stability of CPO under thermal oxidation conditions was evaluated. The main fatty acid in FSO was linolenic acid ( $56.5 \%$ of total fatty acids); while GSO and BSO were rich in linoleic acid, which accounted for 66.8 and $56.8 \%$, respectively. GSO was rich in $\alpha$-tocopherol $(123.0 \mathrm{mg} / \mathrm{kg})$, while $\gamma$-tocopherol was a prevalent isomer in FSO and BSO (137.9 and $128.9 \mathrm{mg} / \mathrm{kg}$, respectively). The total phenolic contents in the oils ranged from $554 \mathrm{mg}$ GAE$/ \mathrm{kg}$ oil (FSO) to $1140 \mathrm{mg}$ GAE/kg oil (BSO). Luteolin, dihydroquercetin and benzoic acids were the dominant bioactives and phenolics in FSO, GSO and BSO, respectively. Based on the oxidative stability index (OSI) value, BSO showed the highest value $(6.14 \mathrm{~h})$ among the other oils. The oxidative stability of FSO and BSO were higher than GSO according to peroxide value (PV) and conjugated diene (CD) values of the oils during storage at $60^{\circ} \mathrm{C}$. Hexanal, 2,4-heptadienal and (E,E)-2,4-heptadienal were the major volatile oxidation compounds (VOC) in FSO. Hexanal and $(E)$-2-heptanal were the main identified VOC in the GSO and BSO under the same oxidation conditions.
\end{abstract}

KEYWORDS: Linum usitatissimum; Nigella sativa; Quality control; SPME-GC/MS; Vegetable oils; Vitis vinifera; Volatile oxidation compounds

RESUMEN: Estabilidad y compuestos de oxidación volátiles de aceites prensados en frío de semillas de uva, lino y comino negro, afectados por la oxidación térmica. Los aceites prensados en frío (CPO) de semilla de uva (OSG), semilla de lino (FSO) y semilla de comino negro (BSO) se analizaron para determinar su perfil de ácidos grasos, tocoferoles, compuestos fenólicos totales, compuestos bioactivos y composición fenólica. Se evaluó la estabilidad del CPO en condiciones de oxidación térmica. El ácido graso principal en FSO fue ácido linolénico (56,5\%), mientras que GSO y BSO fueron ricos en ácido linoleico que representó el 66,8\% y 56,8\%, respectivamente. La OSG fue rica en $\alpha$-tocoferol $(123,0 \mathrm{mg} / \mathrm{kg})$, mientras que el $\gamma$-tocoferol fue el tocoferol mayoritario en el FOE y BSO (137,9 y 128,9 mg/kg, respectivamente). El contenido fenólico total de los aceites varió de $554 \mathrm{mg}$ GAE/ $\mathrm{kg}$ de aceite en FSO a $1140 \mathrm{mg}$ GAE/kg de aceite en BSO. La luteolina, la dihidroquercetina y los ácidos benzoicos fueron los bioactivos y fenólicos dominantes en FSO, GSO y BSO, respectivamente. En base al valor del índice de estabilidad de la oxidación (OSI), BSO mostró el valor más alto $(6,14$ h) entre los otros aceites. La estabilidad oxidativa de FSO y BSO fue mayor que la OSG según el valor de peróxido (PV) y los valores de dieno conjugado (CD) de los aceites durante el almacenamiento a $60^{\circ} \mathrm{C}$. Hexanal, 2,4-heptadienal y (E, E) -2,4-heptadienal fueron los principales compuestos de oxidación volátiles (VOC) en FSO. Hexanal y (E) -2-heptanal fueron los principales VOC identificados en la OSG y la BSO en las mismas condiciones de oxidación.

PALABRAS CLAVE: Aceites vegetales; Compuestos de oxidación volátiles; Control de calidad; Linum usitatissimum; Nigella sativa; $S P M E-G C / M S$; Vitis vinífera

ORCID ID: Kiralan M https://orcid.org/0000-0001-7401-8025, Çalik G https://orcid.org/0000-0002-9031-2344, Kiralan S https://orcid.org/0000-0003-1522-064X, Özaydin A https://orcid.org/0000-0001-7860-8356, Özkan G https:// orcid.org/0000-0002-3333-7537, Ramadan MF https://orcid.org/0000-0002-5431-8503

Citation/Cómo citar este artículo: Kiralan M, Çalik G, Kiralan S, Özaydin A, Özkan G, Ramadan MF. 2019. Stability and volatile oxidation compounds of grape seed, flax seed and black cumin seed cold-pressed oils as affected by thermal oxidation. Grasas Aceites 70 (1), e295. https://doi.org/10.3989/gya.0570181

Copyright: (C2019 CSIC. This is an open-access article distributed under the terms of the Creative Commons Attribution 4.0 International (CC BY 4.0) License. 


\section{INTRODUCTION}

Oils and fats are important components of human nutrition. Grapes (Vitis vinifera) are utilized in different food products and grape seeds are important processing by-products. Grape seeds contain $10-20 \%$ oil, wherein the grape seed oil (GSO) contains high levels of unsaturated fatty acids (Apaydin et al., 2017). Grape seed extracts exhibit antibacterial and antioxidant potential (Da Porto et al., 2013). The unsaponifiable matter of GSO contains high levels of phytosterols. GSO exhibited many pharmaceutical properties, such as the prevention of thrombosis, the inhibition of cardiovascular diseases, properties against the oxidation of lowdensity lipoproteins (LDL), the dilation of blood vessel, cholesterol reduction, and the regulation of the autonomic nerve (Apaydin et al., 2017). Flax (Linum usitatissimum) is a commercially important oilseed crop worldwide. Flaxseed oil (FSO) contains high levels of $n-3$ fatty acids, which are linked to the prevention of cardiovascular diseases and blood pressure (Wei et al., 2015; Tańska et al., 2016). The production of high-quality cold-pressed oils (CPO) from flaxseed is difficult because of its high levels of polyunsaturated fatty acids (PUFA, $\mathrm{ca} .50 \%$ of the total fatty acids in FSO). Studies have been reported on the physicochemical and biological properties of black cumin (Nigella sativa) oil (Ramadan, 2007; Ramadan et al., 2012; Kiralan et al., 2014). Black cumin seed oil (BSO) is rich in bioactive thymoquinone, phytosterols, tocols as well as essential fatty acids (Ramadan, 2013).

Cold-pressing extraction is a solvent-free technique for oil production which is applied to seeds at low temperatures (Parker et al., 2003; Yu et al., 2005; Van Hoed et al., 2006; Siger et al., 2008; Ramadan et al., 2012; Prescha et al., 2014; Ramadan, 2013, Kiralan et al., 2014; Kiralan et al., 2018). In the process of cold-pressing, oil recovery is lower than in solvent extraction or hot-pressing techniques. CPO are important and rich sources of essential fatty acids, phenolics, sterols, tocols, carotenoids, and bioactive phytochemicals with health-promoting properties (Ramadan, 2013). Moreover, CPO have a characteristic taste, aroma and color (Matthäus and Brühl, 2003; Emir et al., 2014). Therefore, CPO could be classified as a "natural product" and consumed without a refining process.

Cold-pressing could avoid the deterioration of the thermo-sensitive compounds, wherein CPO could retain more bioactive compounds including pro-oxidant (i.e. hydroperoxides, free fatty acids, and chlorophylls) (Parry et al., 2005, Ramadan 2013; Wei et al., 2015; Kiralan and Ramadan, 2016). The fatty acid profile and other compounds such as phenolics, sterols and tocols affect lipid oxidation (Koski et al., 2002; Parker et al., 2003; Ramadan 2013; Kiralan and Ramadan, 2016). The stability of
CPO is often from 6 to 12 months, which is limited by the amounts of PUFA, the antioxidant profile of the oil and the storage conditions (Choe and Min, 2006; Prescha et al., 2014).

Thermal and photo oxidation of $\mathrm{CPO}$ were previously determined using different techniques (Kiralan and Ramadan, 2016; Wroniak et al., 2016, Takeyama and Fukushima, 2013). In addition, headspace analysis can also be used for that purpose by determining some key volatile compounds which are markers for oxidation (Gromadzka et al., 2008; Vujasinovic et al., 2010; Lutterodt et al., 2011; Ramadan, 2013).

The goals of this research were to assess and compare the oxidative stability of selected $\mathrm{CPO}$ including flax seed oil (FSO), grape seed oil (GSO) and black cumin seed oil (BSO) under accelerated thermal oxidation conditions such as heating at $60{ }^{\circ} \mathrm{C}$ (Schaal oven test) or higher (Rancimat test at $110{ }^{\circ} \mathrm{C}$ ). Oxidative stability parameters including conjugated diene (CD), and peroxide value (PV) were used to detect the oxidation during storage for six days. In addition, VOC were determined as oxidation markers in the $\mathrm{CPO}$ as affected by storage under thermal oxidation $\left(60^{\circ} \mathrm{C}\right)$ for 6 days.

\section{MATERIALS AND METHODS}

\subsection{Oils and chemicals}

Flaxseed, grape seed and black cumin seed CPO were obtained from a local cold-pressing company (Oneva Cold Pressing, Istanbul, Turkey). Chemicals and solvents with the highest purity available were used without further purification.

\subsection{Accelerated thermal oxidation tests}

\subsubsection{Rancimat Test}

The oxidative stability index (OSI) values of CPO were determined with the Rancimat assay according to AOCS 111 Official Method Cd 12b-92. (1997). The oil stability index (OSI) value was calculated and expressed as the induction time (h), measured by a Rancimat 743 apparatus (Metrohm) using $3 \mathrm{~g}$ of CPO sample heated at $110^{\circ} \mathrm{C}$ with an air flow of $20 \mathrm{~L} / \mathrm{h}$.

\subsubsection{Schaal oven test}

Three grams of CPO sample were weighed and placed in a $20-\mathrm{mL}$ brown headspace vial capped with a Teflon-lined septum. The oxidation was performed for 6 days in a forced-draft air oven at $60^{\circ} \mathrm{C}$. Samples were analyzed daily for conjugated diene (CD), peroxide value (PV), and VOC to monitor the oxidative stability. 


\subsection{CD and $P V$ values}

CD and PV values of CPO during thermal oxidation at $60{ }^{\circ} \mathrm{C}$ were measured according to AOCS methods Cd 8-53 and Cd 18-90 (AOCS, 1997).

\subsection{GC analysis of fatty acid composition}

Fatty acid methyl esters (FAME) were prepared according to IUPAC (1987). GC analysis was carried out with a Shimadzu GC-2010 chromatograph equipped with a fused capillary DB-23 fused-silica column (0.25 mm i.d., $60 \mathrm{~m}, 0.25 \mu \mathrm{m}$ film thickness, Agilent J\&W, USA). The carrier gas was helium at a flow rate of $0.70 \mathrm{~mL} / \mathrm{min}$. The column temperature was set to isothermal at $190^{\circ} \mathrm{C}$ for $95 \mathrm{~min}$, wherein the injector and detector temperatures were $230{ }^{\circ} \mathrm{C}$ and $240{ }^{\circ} \mathrm{C}$, respectively. FAME peak areas were identified by the comparison of retention times with reference standards.

\subsection{Total phenolic content (TPC)}

Aliquots of CPO were dissolved in $n$-hexane $(5 \mathrm{~mL})$ and mixed with $10 \mathrm{~mL}$ methanol: water $(80: 20, \mathrm{v} / \mathrm{v})$ in a glass tube for two $\mathrm{min}$ in a vortex (Ramadan et al., 2012). After centrifugation for $10 \mathrm{~min}$ at $3000 \mathrm{rpm}$, the hydroalcoholic extract was separated from the lipid phase using a Pasteur pipette and then combined and concentrated in vacuo at $30{ }^{\circ} \mathrm{C}$. The oily residue was re-dissolved in $10 \mathrm{~mL}$ methanol: water $(80: 20, \mathrm{v} / \mathrm{v})$ and the extraction process was repeated three times. Hydroalcoholic extracts were re-dissolved in acetonitrile $(15 \mathrm{~mL})$ and the mixture was washed three times with $n$-hexane (15 mL each). Purified phenolics were concentrated in vacuo at $30{ }^{\circ} \mathrm{C}$ and then dissolved in methanol. The phenolic extracts $(40 \mu \mathrm{L})$ and $30 \mathrm{~mL}$ of water were poured into a tube. $200 \mu \mathrm{L}$ of Folin-Ciocalteu reagent were added to the mixture. After $7.5 \mathrm{~min}, 600 \mu \mathrm{L}$ of sodium carbonate $(38 \%)$ were mixed into the solution and the mixture was left for $180 \mathrm{~min}$ at room temperature. The absorbance was measured at $765 \mathrm{~nm}$ using a UV-VIS spectrophotometer (PG Instruments, England). Gallic acid was used as a standard and TPC was calculated and expressed as mg GAE/kg oil.

\subsection{HPLC analysis of bioactives and phenolic compounds}

Phenolic and bioactive compounds were measured by reversed-phase high-performance liquid chromatography (RP-HPLC, Shimadzu Scientific Instruments, Tokyo, Japan). Identification and quantification were performed with a ShimadzuLC10ADvp pump, a CTO-10Avp column heater, a Diode Array Detector, SCL-10Avp system controller, DGU-14A degasser and SIL-10ADvp autosampler (Shimadzu, Columbia, MD). Separations were performed at $30^{\circ} \mathrm{C}$ on Agilent-Eclipse XDB $\mathrm{C}-18$ reversed-phase column $(4.6 \mathrm{~mm}$ length, $250 \mathrm{~mm}, 5 \mu \mathrm{m}$ particle size). The mobile phases were A: $2.0 \%$ acetic acid in distilled water and B: methanol. The flow rate was $0.8 \mathrm{~mL} / \mathrm{min}$. For analysis, $25 \mathrm{mg}$ of the extract was dissolved in $1 \mathrm{~mL}$ methanol wherein the injection volume was $10 \mu \mathrm{L}$. A modified gradient elution of two solvents was used: solvent A consisted of acetic acid: water $(3: 97, \mathrm{v} / \mathrm{v})$, solvent B: methanol. The gradient program used is given in Table 1 according to Caponio et al., (2001). Identification and quantitative analyses were performed by comparison with standards. The limit of detection (LOD) and the limit of quantification (LOQ) were 0.01 and $0.02 \mu \mathrm{g} / \mathrm{mL}$ for gallic acid, 0.05 and $0.16 \mu \mathrm{g} / \mathrm{mL}$ for protocatechuic acid, 0.02 and $0.05 \mu \mathrm{g} / \mathrm{mL}$ for caffeic acid, 0.005 and $0.01 \mu \mathrm{g} / \mathrm{mL}$ for $p$-hydroxy benzoic acid, 0.02 and $0.07 \mu \mathrm{g} / \mathrm{mL}$ for chlorogenic acid, 0.01 and $0.02 \mu \mathrm{g} / \mathrm{mL}$ for syringic acid, 0.01 and 0.03 $\mu \mathrm{g} / \mathrm{mL}$ for $p$-coumaric acid, 0.01 and $0.02 \mu \mathrm{g} / \mathrm{mL}$ for ferulic acid, 0.06 and $0.19 \mu \mathrm{g} / \mathrm{mL}$ for benzoic acid, 0.005 and $0.01 \mu \mathrm{g} / \mathrm{mL}$ for $o$-coumaric acid, 0.10 and $0,31 \mu \mathrm{g} / \mathrm{mL}$ for catechin, 0.05 and 0.15 $\mu \mathrm{g} / \mathrm{mL}$ for (')-epicatechin, 0.03 and $0,10 \mu \mathrm{g} / \mathrm{mL}$ for vanilic acid, 0.01 and $0.04 \mu \mathrm{g} / \mathrm{mL}$ for vanilin, 0.06 and $0.18 \mu \mathrm{g} / \mathrm{mL}$ for rutin, 0.03 and $0.08 \mu \mathrm{g} / \mathrm{mL}$ for apigenin, 0.11 and $0.32 \mu \mathrm{g} / \mathrm{mL}$ for quercetin, 0.03 and $0.10 \mu \mathrm{g} / \mathrm{mL}$ for luteolin and 0.02 and $0.06 \mu \mathrm{g} /$ $\mathrm{mL}$ for campherol, 0.73 and $2.21 \mu \mathrm{g} / \mathrm{mL}$ for thymoquinone, 2.49 and $7.56 \mu \mathrm{g} / \mathrm{mL}$ for thymol, 0.12 and $0.35 \mu \mathrm{g} / \mathrm{mL}$ for acacetin, respectively. The levels of phenolics in the extracts were calculated as $\mathrm{mg} / \mathrm{kg}$ oil. All extractions and chromatographic analyses were performed in triplicate and the results were averaged.

TABLE 1. Solvent gradient conditions of HPLC

\begin{tabular}{lrcccccccccrrr}
\hline $\begin{array}{l}\text { Time } \\
\text { (min) }\end{array}$ & $\mathbf{3}$ & $\mathbf{2 0}$ & $\mathbf{2 8}$ & $\mathbf{3 5}$ & $\mathbf{5 0}$ & $\mathbf{6 0}$ & $\mathbf{6 2}$ & $\mathbf{7 0}$ & $\mathbf{7 3}$ & $\mathbf{7 5}$ & $\mathbf{8 0}$ & $\mathbf{9 0}$ \\
\hline A \%* & 93 & 72 & 75 & 70 & 70 & 67 & 58 & 50 & 30 & 20 & 0 & 93 \\
B \% & 7 & 28 & 25 & 30 & 30 & 33 & 42 & 50 & 70 & 80 & 100 & 7 \\
\hline
\end{tabular}

*Solvent A: acetic acid:water $(3: 97, \mathrm{v} / \mathrm{v})$; solvent B: methanol. 


\subsection{HPLC analysis of tocopherols $(\alpha, \beta, \gamma$, and $\delta)$}

Tocopherols were analyzed according to the American Oil Chemists' Society method Ce 8-89 (AOCS, 2003). Tocopherols $(\alpha, \beta, \gamma$, and $\delta$ ) were analyzed using normal-phase HPLC by the direct injection of CPO samples dissolved in a mixture (95:5, v/v) of heptane:tetrahydrofuran (THF). HPLC analysis was carried out with an SCL-10Avp System controller, LC-10ADvp pump, SIL-10ADvp Autosampler, CTO-10 Avp column heater and fluorescence detector set at $295 \mathrm{~nm}$ for excitation and $330 \mathrm{~nm}$ for emission. The $150 \mathrm{~cm}$ x $4.6 \mathrm{~mm}$ i.d. column filled with Supelcosil Luna, 5m (Supelco, Bellefonte, PA) was used. The mobile phase was a mixture of heptane:THF $(95: 5, \mathrm{v} / \mathrm{v})$ at a flow rate of $1.2 \mathrm{~mL} / \mathrm{min}$ wherein the injection volume was $10 \mathrm{~mL}$. The standard samples used for identification and quantification were $\alpha, \beta, \gamma$ and $\delta$-tocopherols (Sigma, St. Louis, Mo., USA). The data were analyzed and integrated using the Shimadzu Class-VP Chromatography Lab Automated Software. The levels of tocopherols in CPO were calculated as $\mathrm{mg} /$ $\mathrm{kg}$ oil using the external calibration curves obtained for each tocopherol standard. The LOD and the LOQ were 0.03 and $0.08 \mu \mathrm{g} / \mathrm{mL}$ for $\alpha$-tocopherol, 0.02 and $0.06 \mu \mathrm{g} / \mathrm{mL}$ for $\beta$-tocopherol, 0.04 and 0.13 $\mu \mathrm{g} / \mathrm{mL}$ for $\gamma$-tocopherol, and 0.03 and $0.08 \mu \mathrm{g} / \mathrm{mL}$ for $\delta$-tocopherol. The chromatographic analysis was performed three times and the results were averaged.

\subsection{GC-MS analysis of VOC}

CPO samples stored under accelerated oxidation conditions at $60{ }^{\circ} \mathrm{C}$ were used to determine volatile compounds and VOC. Equilibration took place for 15 min at $35^{\circ} \mathrm{C}$ followed by extraction $(45 \mathrm{~min}$ ) from the headspace at $35^{\circ} \mathrm{C}$ then a $10 \mathrm{~min}$ of desorption in the GC injection port with the aid of a CTC Combi PAL (CTC Analytics AG, Zwingen, Switzerland) autosampler with $75 \mu \mathrm{m}$ carboxen/polydimethylsiloxane solid-phase micro-extraction (SPME) fiber. GC-MS analyses were carried out with an Agilent system (GC 7890, MS 5975 N MSD, Santa Clara, CA, USA) using an analytical column of medium polarity (DB-624, $30 \mathrm{~m}$ length $\times 0.25 \mathrm{~mm}$ ID $\times 1.4 \mu \mathrm{m}$ film thickness, Agilent Technologies, CA, USA). The following temperature program was applied: hold for $5 \mathrm{~min}$ at $40^{\circ} \mathrm{C}$; $3{ }^{\circ} \mathrm{C} / \mathrm{min}$ up to $110^{\circ} \mathrm{C} ; 4^{\circ} \mathrm{C} / \mathrm{min}$ up to $150{ }^{\circ} \mathrm{C} ; 10^{\circ} \mathrm{C} /$ min up to $210^{\circ} \mathrm{C}$ and hold for $12 \mathrm{~min}$. The temperatures for the injection port, ion source, quadrupole, and interface were $250^{\circ} \mathrm{C}, 230^{\circ} \mathrm{C}, 150^{\circ} \mathrm{C}$, and $240^{\circ} \mathrm{C}$, respectively. Mass spectra were recorded in full scan mode at the electron impact of $70 \mathrm{eV}$ with a scan range from $\mathrm{m} / \mathrm{z} 41$ to 400 . The identification of volatile compounds was made by comparing mass spectra, Kovats index (KI) with the authentic standards and published data, as well as by comparing their mass spectra with Wiley7.0 (Wiley, NY, USA) and the mass spectrometry library of Nist 05 (National Institute of Standards and Technology, Gaithersburg, MD, USA). The KI parameters were calculated using the n-hydrocarbons (C4 to C20) series. One vial for daily assessment from sets of replicate vials for every CPO was used throughout the study.

\subsection{Statistical analysis}

Results are shown and expressed in terms of the mean and standard deviations. Significant differences were calculated using ANOVA in combination with Duncan's test with a significance level of $\alpha=0.05$.

\section{RESULTS AND DISCUSSION}

\subsection{Composition of CPO}

The fatty acid profiles of the CPO samples are shown in Table 2. The main fatty acids in FSO were linolenic acid (56.5\%), followed by oleic acid $(18.0 \%)$ and linoleic acid (15.9\%). The fatty acid compositions of GSO and BSO included linoleic acid (66.8\% and $56.8 \%$, respectively) as the major fatty acid, followed by oleic acid $(19.5 \%$ and $23.8 \%)$ and palmitic acid $(8.25 \%$ and $12.4 \%)$, respectively. The fatty acid composition of FSO was in agreement with those reported by others (Brühl et al., 2008; IvanovaPetropulos et al., 2015; Raczyk et al., 2016; Teh and Birch, 2013). The results of the FAME profile of GSO fall within similar ranges reported (Tuberoso et al., 2007; Lutterodt et al., 2011; Wen et al., 2016). In addition, the fatty acid composition of BSO was in accordance with those previously reported in the literature (Cheikh-Rouhou et al., 2007; Lutterodt et al., 2010; Ramadan et al., 2012).

The TPC of CPO is given in Table 3. The highest TPC was found in BSO $(1140 \mathrm{mg} / \mathrm{kg}$ oil $)$, while FSO contained the lowest TPC $(554.4 \mathrm{mg} / \mathrm{kg})$. The TPC in BSO was similar to the values $(1.02-1.40 \mathrm{mg}$ GAE/g) reported by Lutterodt et al., (2010). The TPC of FSO was lower than the values reported by Kasote et al., (2013) who determined that the TPC of cold-pressed linseed oils ranged from 10 to 26 $\mathrm{mg}$ GAE/100 g oil. In addition, the TPC of coldpressed GSO was similar to the values $(0.16-0.80 \mathrm{mg}$ GAE/g) reported by Lutterodt et al., (2011).

The phenolic and bioactive compound profiles of CPO are also given in Table 3. In the FSO, luteolin and apigenin were detected and their amounts were 0.76 and $0.02 \mathrm{mg} / \mathrm{kg}$ oil, respectively. In GSO, 8 compounds including vanillin, vanillic acid, $p$-coumaric acid, dihydroquercetin, luteolin, campherol, apigenin and acacetin were identified. GSO contained the highest dihydroquercetin content $(2.49 \mathrm{mg} / \mathrm{kg}$ oil). Luteolin and apigenin were not detected in FSO or GSO in the research of Tuberos et al., (2007). The differences in bioactive and phenolic compound profiles could be due to differences 
TABLE 2. Fatty acid composition (relevant content, \%) of $\mathrm{CPO}(\mathrm{n}=2$, mean $\pm \mathrm{SD})$

\begin{tabular}{lccc}
\hline Fatty acid & $\begin{array}{c}\text { Flax seed oil } \\
\text { (FSO) }\end{array}$ & $\begin{array}{c}\text { Grape seed oil } \\
\text { (GSO) }\end{array}$ & $\begin{array}{c}\text { Black cumin } \\
\text { seed oil (BSO) }\end{array}$ \\
\hline C12:0 & $0.04 \pm 0.00^{*}$ & $0.05 \pm 0.00$ & $0.14 \pm 0.00$ \\
C14:0 & $0.02 \pm 0.00$ & $0.01 \pm 0.00$ & $0.03 \pm 0.00$ \\
C16:0 & $5.43 \pm 0.00$ & $8.25 \pm 0.00$ & $12.46 \pm 0.48$ \\
C16:1 & $0.05 \pm 0.00$ & $0.09 \pm 0.00$ & $0.18 \pm 0.01$ \\
C17:0 & $0.06 \pm 0.00$ & $0.07 \pm 0.00$ & $0.07 \pm 0.01$ \\
C17:1 & $0.04 \pm 0.00$ & $0.03 \pm 0.00$ & $0.04 \pm 0.00$ \\
C18:0 & $3.50 \pm 0.00$ & $4.29 \pm 0.00$ & $3.27 \pm 0.18$ \\
C18:1 & $18.01 \pm 0.02$ & $19.58 \pm 0.09$ & $23.85 \pm 0.04$ \\
C18:2 & $15.95 \pm 0.01$ & $66.86 \pm 0.07$ & $56.80 \pm 0.56$ \\
C18:3 & $56.55 \pm 0.02$ & $0.28 \pm 0.00$ & $0.23 \pm 0.00$ \\
C20:0 & $0.11 \pm 0.00$ & $0.14 \pm 0.00$ & $0.20 \pm 0.00$ \\
C20:1 & $0.10 \pm 0.00$ & $0.14 \pm 0.00$ & $0.28 \pm 0.01$ \\
C20:2 & $0.03 \pm 0.00$ & $\mathrm{ND} *$ & $2.41 \pm 0.03$ \\
C22:0 & $0.04 \pm 0.00$ & $0.01 \pm 0.00$ & $\mathrm{ND}$ \\
C24:0 & $0.09 \pm 0.00$ & $0.21 \pm 0.01$ & $0.09 \pm 0.00$ \\
\hline
\end{tabular}

*ND: not detected

TABLE 3. TPC, bioactive compounds, phenolic compounds and tocopherol composition of CPO $(n=2$, mean \pm SD)

\begin{tabular}{|c|c|c|c|}
\hline & Flax seed oil & $\begin{array}{c}\text { Grape seed } \\
\text { oil }\end{array}$ & $\begin{array}{c}\text { Black cumin } \\
\text { oil }\end{array}$ \\
\hline \multicolumn{4}{|c|}{ TPC (mg GAE/kg oil) } \\
\hline & $554.4 \pm 17.86^{*}$ & $924.2 \pm 20.41$ & $1140.4 \pm 14.67$ \\
\hline \multicolumn{4}{|c|}{ Bioactive compounds and phenolic compounds (mg/kg oil) } \\
\hline $\begin{array}{l}p \text {-hydrobenzoic } \\
\text { acid }\end{array}$ & $\mathrm{ND}^{*}$ & ND & $1.47 \pm 0.00$ \\
\hline Vanillic acid & ND & $0.39 \pm 0.00$ & ND \\
\hline Vanillin & ND & $0.33 \pm 0.00$ & ND \\
\hline$p$-coumaric acid & ND & $0.08 \pm 0.01$ & ND \\
\hline Benzoic acid & ND & ND & $228.5 \pm 9.68$ \\
\hline Dihydroquercetin & ND & $2.49 \pm 0.02$ & ND \\
\hline Luteolin & $0.76 \pm 0.01$ & $0.67 \pm 0.00$ & $2.12 \pm 0.02$ \\
\hline Campherol & ND & $0.34 \pm 0.01$ & $0.28 \pm 0.00$ \\
\hline Apigenin & $0.02 \pm 0.01$ & $0.01 \pm 0.01$ & $0.17 \pm 0.01$ \\
\hline Thymoquinone & ND & ND & $97.58 \pm 0.14$ \\
\hline Thymol & ND & ND & $4.80 \pm 0.20$ \\
\hline Acacetin & ND & $0.31 \pm 0.04$ & ND \\
\hline \multicolumn{4}{|c|}{ Tocopherols (mg/kg oil) } \\
\hline$\alpha$-tocopherol & $6.33 \pm 0.01^{* * *}$ & $123.0 \pm 1.76$ & $22.04 \pm 0.62$ \\
\hline$\gamma$-tocopherol & $137.9 \pm 1.19$ & $16.70 \pm 0.01$ & $128.9 \pm 1.61$ \\
\hline$\delta$-tocopherol & $3.73 \pm 0.01$ & $0.56 \pm 0.01$ & $0.61 \pm 0.01$ \\
\hline
\end{tabular}

*ND: not detected in cultivar, variety, location and extraction conditions. The most abundant compound in black cumin oil was benzoic acid $(228.5 \mathrm{mg} / \mathrm{kg}$ oil), followed by thymoquinone $(97.58 \mathrm{mg} / \mathrm{kg}$ oil). The amounts of thymoquinone and benzoic acid in our study were higher than those reported by Kiralan et al., (2014) who determined that the levels of benzoic acid and thymoquinone were 4.15 and $14.4 \mu \mathrm{g} / \mathrm{g}$, respectively.

Table 3 shows the tocopherol contents of CPO. $\gamma$-Tocopherol was found as the major tocopherol isomer in the FSO $(137.9 \mathrm{mg} / \mathrm{kg}$ oil) and BSO $(128.9 \mathrm{mg} /$ $\mathrm{kg}$ oil). The main tocopherol in the GSO was the $\alpha$ form $(123.0 \mathrm{mg} / \mathrm{kg}$ oil). The $\gamma$ - tocopherol content in the FSO was in accordance with the values $(10.5-15.0 \mathrm{mg} / 100 \mathrm{~g}$ seed) reported by Choo et al., (2007). The $\alpha$-tocopherol value in the GSO in our work showed similarity to that determined by Fernandes et al., (2013) for oils of Portuguese GSO (85.5-244 mg/kg). The content of $\gamma$-tocopherol in the BSO was lower $(0.225 \mathrm{~g} / \mathrm{kg})$ than that reported by Ramadan and Moersel (2004). The differences in the contents and composition of tocopherols in the CPO under study may be due to differences in cultivar, variety and origin of the investigated seeds.

\subsection{Stability of CPO as affected by thermal oxidation}

The OSI values of CPO according to the Rancimat test revealed that BSO had the highest OSI (6.14 h), followed by GSO (4.06 h), while FSO had the lowest ( $2.63 \mathrm{~h}$ ) OSI value. The results can be explained by the fatty acid profile of the CPO under study. The oxidative stability of FSO was very low in comparison to the other oils under Rancimat oxidation conditions. This might be explained by the fact that FSO is rich in linolenic acid, which has a high susceptibility to oxidation. Likewise, BSO had a better OSI value than GSO. GSO contained a higher level $(66.8 \%)$ of linoleic acid than BSO (56.8\%).

The OSI of FSO was higher than the OSI values (1.43-1.52 h) reported by Bozan and Temelli (2008). The results obtained for GSO heated at $110{ }^{\circ} \mathrm{C}$ were lower than those reported by Hassanien et al., (2014) for hexane-extracted GSO ( $8 \mathrm{~h})$. However, the OSI of GSO was similar to those reported for refined GSO (3.3-5.3 h) under similar conditions (Hidalgo et al., 2002). The OSI value for BSO was lower than that $(16.9 \mathrm{~h})$ reported by Hassanien et al., (2014) and (ca. 22 h) Rudzińska et al., (2016), but higher than that reported by Kiralan et al., (2014) for coldpressed BSO (3.48 h). These differences in OSI values might be due to the composition and amounts of natural antioxidants in the CPO samples.

The changes in PV in CPO during storage for 6 days at $60{ }^{\circ} \mathrm{C}$ are shown in Figure 1 . The PV values for fresh CPO were 1.82, 12.2 and 26.5 for FSO, GSO and BSO, respectively. After $48 \mathrm{~h}$ of storage under oxidation conditions, the PV of FSO increased sharply and reached up to $29.97 \mathrm{meq}_{2} /$ 


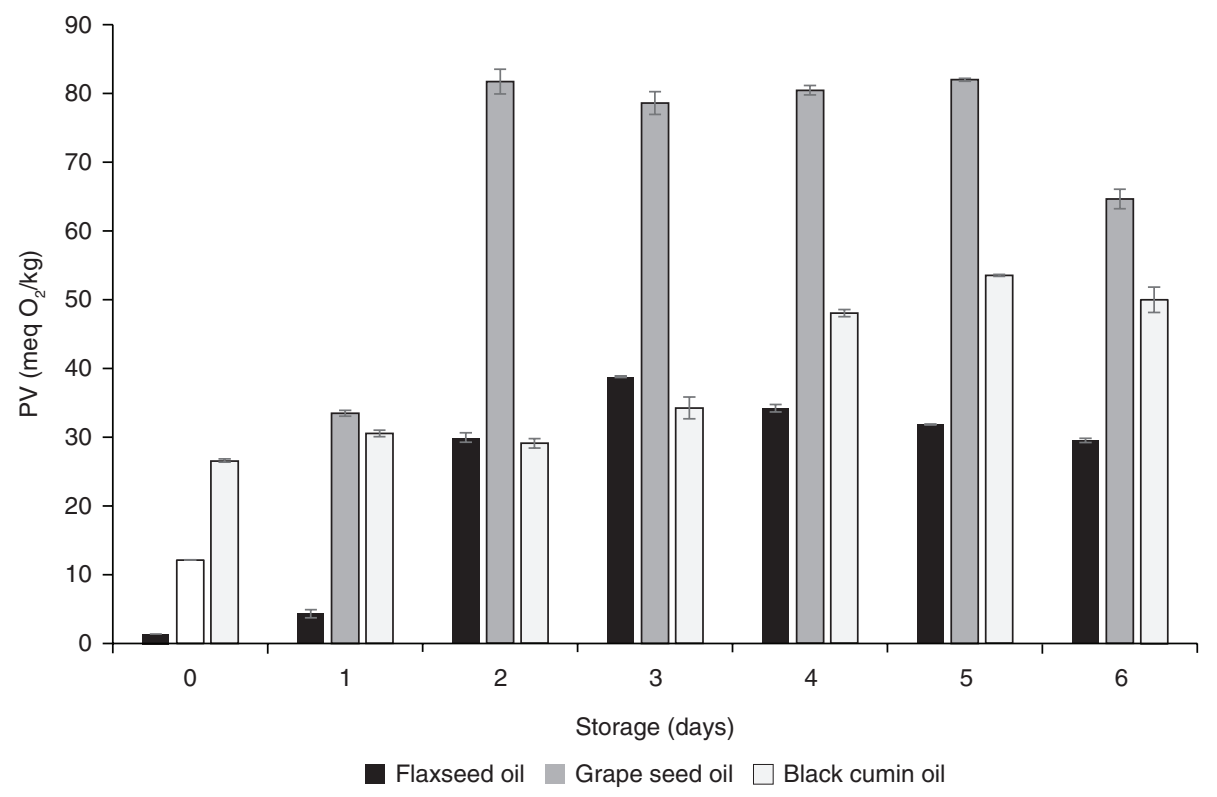

FIGURE 1. Changes in the PV of $\mathrm{CPO}$ during storage at $60^{\circ} \mathrm{C}(\mathrm{n}=2$, mean $\pm \mathrm{SD})$. Error bars show the variations of two determinations in terms of standard deviation.

$\mathrm{kg}$. After that, PV values were recorded to show stabile behavior till the end of storage period. In addition, the PV values of GSO increased sharply after $48 \mathrm{~h}$ of storage and the highest values were recorded (81.6 meq $\mathrm{O}_{2} / \mathrm{kg}$ ). After $48 \mathrm{~h}$ of storage, the PV values for GSO slightly decreased to $c a$. $87-81 \mathrm{meq}$ $\mathrm{O}_{2} / \mathrm{kg}$ until the $5^{\text {th }}$ day of storage, when the PV of GSO decreased to 64 meq $\mathrm{O}_{2} / \mathrm{kg}$. In the $\mathrm{BSO}$, the PV increased gradually with increasing storage period. The highest PV value $\left(53.5 \mathrm{meq} \mathrm{O}_{2} / \mathrm{kg}\right.$ ) for $\mathrm{BSO}$ was measured after 5 days of storage. Based on PV values, it could be concluded that BSO had the greatest oxidative stability among the CPO under study.

The changes in $\mathrm{CD}\left(\mathrm{K}_{232}\right.$ values) of the $\mathrm{CPO}$ stored for 6 days under thermal oxidation are exhibited in Figure 2. The rate of increase in $\mathrm{K}_{232}$ values showed similar behavior to that of the PV values. The $\mathrm{K}_{232}$ values for FSO increased gradually with the increase in storage time, reaching the maximum value (6.41) at the end of the storage period. There was a significant increase in the $\mathrm{K}_{232}$ values for the GSO with increasing storage time. In addition, a stable increase in the $\mathrm{K}_{232}$ values of $\mathrm{BSO}$ was observed until the $6^{\text {th }}$ day of storage.

Our CD results for FSO are in agreement with Hamed and Abo-Elwafa (2012), who reported that the PV and CD values of FSO increased sharply when stored at $60{ }^{\circ} \mathrm{C}$. Similar observations on PV and $\mathrm{K}_{232}$ values of GSO stored under thermal conditions have been reported (Jang et al., 2015). In addition, similar increases in PV and CD values have been observed in BSO as affected by thermal oxidation conditions (Kiralan, 2014; Kiralan et al., 2017). However, our results might somehow differ from the results previously reported in the literature. In our experiment, small oil samples were used in headspace vials, as opposed to the use of large amount of oil samples in the above-mentioned literature. In addition, the differences in the results might be due to the distinctive experiment oxidation conditions, genotype and growing condition of plants.

\subsection{Changes in the VOC as affected by thermal oxidation}

An in-depth search in the scientific literature indicated that studying VOC in FSO, BSO and GSO during storage at thermal oxidation conditions had not yet been performed. The changes in the VOC and volatile compounds in $\mathrm{CPO}$ during storage under thermal oxidation conditions are given in Table 4. Six volatile compounds, including aldehydes and alkadienes, are detected in the headspace of FSO. During storage, hexanal was the major compound among VOC. 2,4-heptadienal, and $(E, E)$ 2,4-heptadienal were formed upon oxidation and at the end of the storage period, both compounds increased up to the maximum values of 16.84 and $16.09 \times 10^{6} \mathrm{AU}$, respectively. 2-hexenal, 2,4-hexadienal and $E$-2-heptenal were VOC detected after 3 days of FSO storage and their levels increased with the increase in storage time.

2,4-heptadienal was formed in canola and soybean oil with high linolenate (Snyder et al., 1985). (E,E)-2,4-heptadienal was also identified in soybean oil stored under thermal oxidation conditions (Snyder et al., 1988). Hexanal, 2-hexenal, (E)-2-heptenal, $(E, E)$-2,4-heptadienal and 


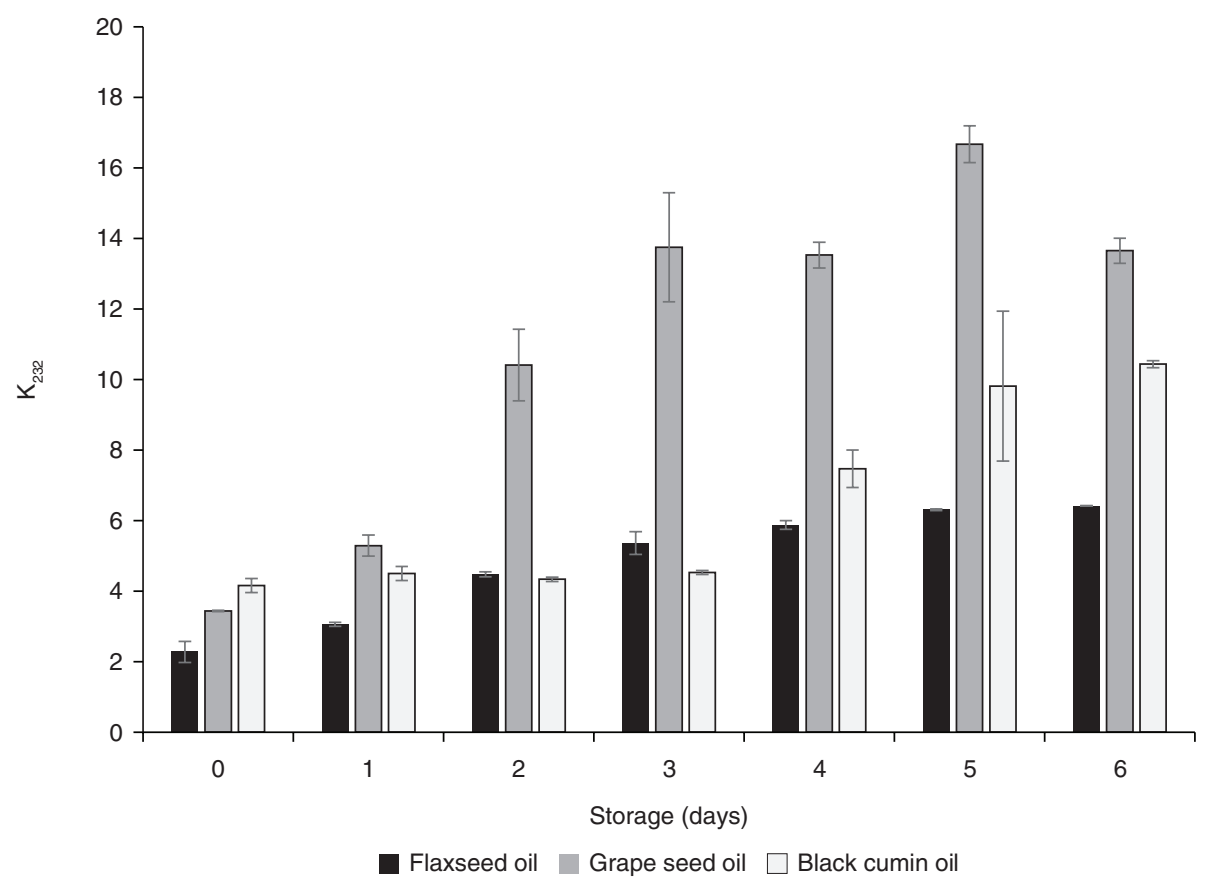

Figure 2. Changes in $\mathrm{CD}$ levels of $\mathrm{CPO}$ during storage at $60^{\circ} \mathrm{C}(\mathrm{n}=2$, mean $\pm \mathrm{SD})$. Error bars show the variations of two determinations in terms of standard deviation.

(E,E)-2,4-hexadienal were detected in fresh FSO without oxidation treatments (Krist et al., 2006; Wei et al., 2015). The results of our study on the VOC in FSO are in agreement with Abuzaytoun and Shahidi (2006) who reported an increase in hexanal levels during the storage of FSO at $60{ }^{\circ} \mathrm{C}$.

Table 4 listed the VOC identified in the GSO during storage. Thirteen compounds were detected, including alkane (2-octene), aldehydes ((E)-2heptenal, hexanal, $(E)$-2-octenal), ketones (3-octanone, 6-methyl-5-hepten-2-one, 2-heptanone, 2-octanone), and alkadienals (2,4-hexadienal, 2,4-heptadienal, 2,4-nonadienal, 2,4-decadienal, $(E, E)$-2,4-decadienal). (E)-2-heptenal was detected as the main VOC during storage, followed by hexanal. At the end of storage, the other most abundant aldehyde found in GSO was $(E)$-2-octenal. In addition, at the end of the storage experiment, diverse alkadienals were formed. However, the levels of these compounds remained limited among the VOC.

Hexanal, $(E)$-2-heptenal and $(E)$-2octenal were determined as the decomposition products of linoleate hydroperoxides (Frankel et al., 1981). The increase rate of forming hexanal and $(E)$-2-heptenal during storage at $60^{\circ} \mathrm{C}$ was observed in the study by Jelen et at., (2000), who reported that the increase in 2-heptenal was more than that in hexanal in the headspace of cold-pressed rapeseed oil at the end of storage $\left(60^{\circ} \mathrm{C}\right)$. No literature report could be found about the volatile compounds of GSO during thermal oxidation but only one published work (Bail et al., 2008) reported on the volatile compounds of nine GSO. In this work (Bail et al., 2008), hexanal, 2-heptanone, $(E)$-2-heptenal and (E)-2-octenal were observed in the volatiles of oil samples. These compounds were also identified in our analyzed coldpressed grape seed oil.

Five VOC were identified in the headspace of BSO during storage as given in Table 4. Most of the identified volatiles were aldehydes and only one ketone (2-heptanone) was detected in the headspace of the BSO sample. Among the aldehydes, hexanal and $(E)$-2-heptenal were formed as the main VOC during storage. Lower contents of 2-hexenal and (E)-2-octenal in the headspace of BSO were identified. The study by Kiralan et al. (2017) concluded that hexanal and $(E)$-2-heptenal were the major VOC formed during the oxidation of $\mathrm{BSO}$ at $60^{\circ} \mathrm{C}$.

\section{CONCLUSIONS}

Based on the results of the Rancimat test, BSO had higher oxidative stability than GSO and FSO. In addition, FSO and BSO showed stronger oxidative stability than GSO after storage at $60{ }^{\circ} \mathrm{C}$. The changes in PV and CD in FSO during storage at $60^{\circ} \mathrm{C}$ were less than in BSO and GSO. The higher stability of FSO and BSO could be related to the levels of $\gamma$-tocopherol and individual bioactives and phenolic compounds in both oils. To the best of our knowledge, this is the first study on the effect of 


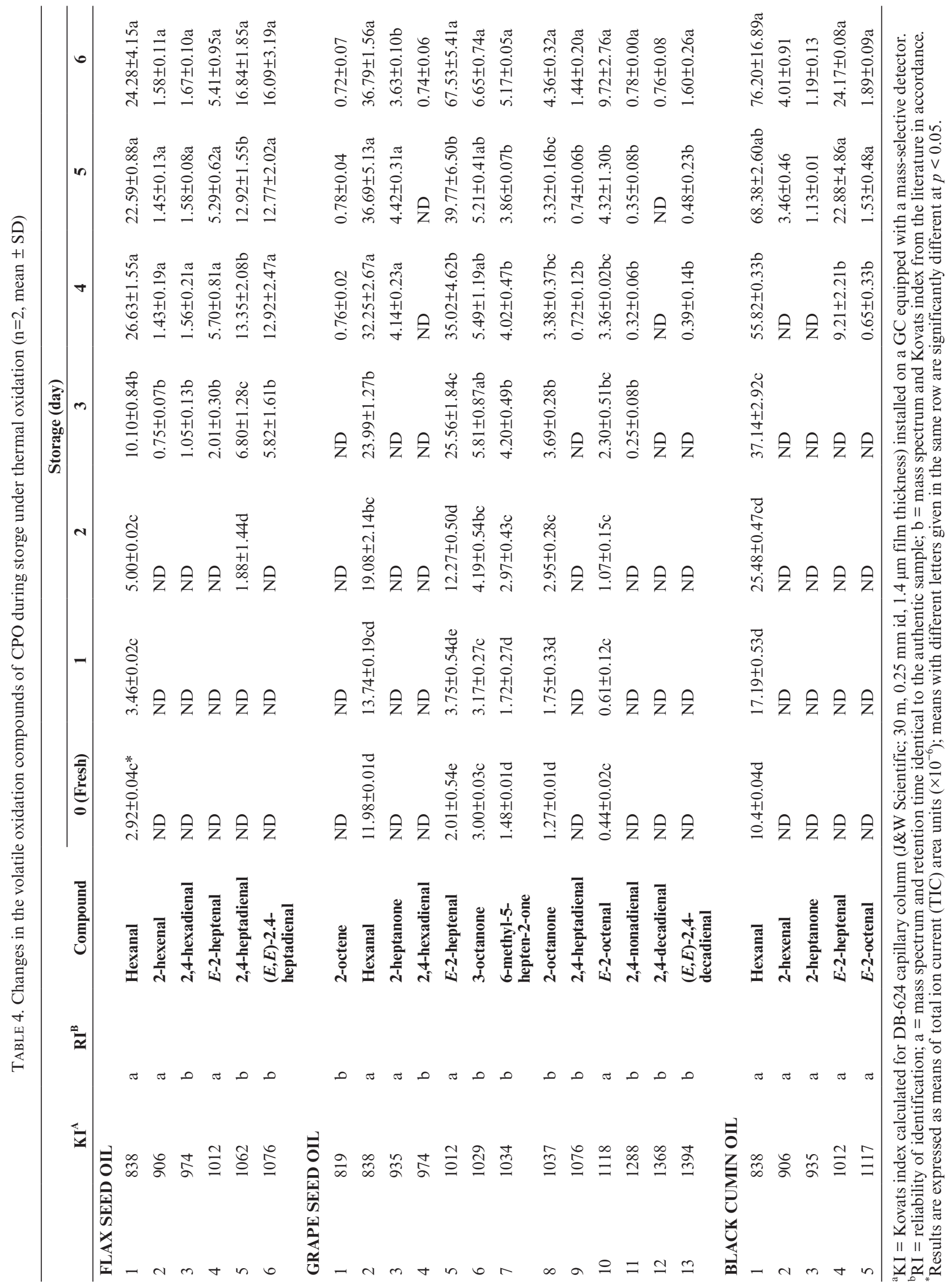


storage under thermal oxidation conditions on the VOC in the selected CPO. The identified VOC could be used as markers for detecting oils under study. The results could be used for the determination of the major and minor bioactive components responsible for the quality of CPO.

\section{ACKNOWLEDGMENTS}

The authors would like to thank the Scientific Research Projects Fund of Abant Izzet Baysal University (Turkey) for providing financial support for the project (contract grant number 2015.09.04.922). The authors also thank Mr. Süha Ersoy (Oneva Cold Pressing, Istanbul, Turkey) for supplying CPO.

Conflict of interest. The authors declare that they have no conflict of interest.

Compliance with ethics requirements. This article does not contain any studies with human or animal subjects.

\section{REFERENCES}

Abuzaytoun R, Shahidi F. 2006. Oxidative stability of flax and hemp oils. J. Am. Oil Chem. Soc. 83, 855-861. https://doi. org/10.1007/s11746-006-5037-7

AOCS. 1997. In: Firestone D (ed) Official Methods and Recommended Practices of the American Oil Chemists' Society, 4th edn. American Oil Chemists' Society, Champaign. The Society.

AOCS. 2003. Official Methods and Recommended Practices of the American Oil Chemist's Society (5th ed.). Champaign, Illinois, U.S.A.

Apaydin D, Demirci AS, Gecgel U. 2017. Effect of gamma irradiation on biochemical properties of grape seeds. $J$. Am. Oil Chem. Soc. 94, 57-67. https://doi.org/10.1007/ s11746-016-2917-3

Bail S, Stuebiger G, Krist S, Unterweger H, Buchbauer G. 2008. Characterisation of various grape seed oils by volatile compounds, triacylglycerol composition, total phenols and antioxidant capacity. Food Chem. 108, 1122-1132. https:// doi.org/10.1016/j.foodchem.2007.11.063

Bozan B, Temelli F. 2008. Chemical composition and oxidative stability of flax, safflower and poppy seed and seed oils. Biores. Technol. 99, 6354-6359. https://doi.org/10.1016/j. biortech.2007.12.009

Brühl L, Matthäus B, Scheipers A, Hofmann T. 2008. Bitter off-taste in stored cold-pressed linseed oil obtained from different varieties. E. J. Lipid Sci. Technol. 110, 625-631. https://doi.org/10.1002/ejlt.200700314

Caponio F, Gomes T, Pasqualone A. 2001. Phenolic compounds in virgin olive oils: influence of the degree of olive ripeness on organoleptic characteristics and shelf-life. $E$. Food Res. Technol. 212, 329-333. https://doi.org/10.1007/ s002170000268

Cheikh-Rouhou S, Besbes S, Hentati B, Blecker C, Deroanne C, Attia H. 2007. Nigella sativa L.: Chemical composition and physicochemical characteristics of lipid fraction. Food Chem. 101, 673-681. https://doi.org/10.1016/j. foodchem.2006.02.022

Choe E, Min DB. 2006. Mechanisms and factors for edible oil oxidation. Com. Rev. in Food Sci. Food Saf. 5, 169-186. https://doi.org/10.1111/j.1541-4337.2006.00009.x

Choo W-S, Birch J, Dufour J-P. 2007. Physicochemical and quality characteristics of cold-pressed flaxseed oils. $J$.
Food Comp. Anal. 20, 202-211. https://doi.org/10.1016/j. jfca.2006.12.002

Emir DD, Güneşer O, Yilmaz E. 2014. Cold pressed poppy seed oils: Sensory properties, aromatic profiles and consumer preferences. Grasas Aceites 65, e029. https://doi. org/10.3989/gya.109213

Fernandes L, Casal S, Cruz R, Pereira JA, Ramalhosa E. 2013. Seed oils of ten traditional Portuguese grape varieties with interesting chemical and antioxidant properties. Food Res. Int. 50, 161-166. https://doi.org/10.1016/j. foodres.2012.09.039

Frankel EN, Neff WE, Selke E. 1981. Analysis of autoxidized fats by gas chromatography-mass spectrometry: VII. Volatile thermal decomposition products of pure hydroperoxides from autoxidized and photosensitized oxidized methyl oleate, linoleate and linolenate. Lipids 16, 279-285. https://doi.org/10.1007/BF02534950

Gromadzka J, Wardencki W, Lores M, LLompart M, FernandezAlvarez M, Lipinska K. 2008. Investigation of edible oils oxidation stability using photooxidation and SPME-GC method for determination of volatile compounds-preliminary investigation. Pol. J. Food Nut. Sci. 58, 321-324.

Hamed SF, Abo-Elwafa GA. 2012. Enhancement of oxidation stability of flax seed oil by blending with stable vegetable oils. J. App. Sci. Res. 8, 5039-5048.

Hassanien MMM, Abdel-Razek AG, Rudzińska M, Siger A, Ratusz K, Przybylski R. 2014. Phytochemical contents and oxidative stability of oils from non-traditional sources. Eur. J. Lipid Sci. Technol. 116, 1563-1571. https://doi. org/10.1002/ejlt.201300475

Hidalgo FJ, Gómez G, Navarro JL, Zamora R. 2002. Oil stability prediction by high-resolution ${ }^{13} \mathrm{C}$ nuclear magnetic resonance spectroscopy. J. Agric. Food Chem. 50, 5825-5831. https://doi.org/10.1021/jf0256539

IUPAC. 1987. Standard methods for the analysis of oils, fats and derivatives: International Union of Pure and Applied Chemistry (IUPAC) Method 2.301, Report of IUPAC Working Group WG 2/87 Blackwell Scientific Publications, Palo Alto, CA, USA.

Ivanova-Petropulos V, Mitrev S, Stafilov T, Markova N, Leitner E, Lankmayr E, Siegmund B. 2015. Characterisation of traditional Macedonian edible oils by their fatty acid composition and their volatile compounds. Food Res. Int. 77, 506-514. https://doi.org/10.1016/j.foodres.2015.08.014

Jang S, Lee J, Choi WS. 2015. Oxidative stability of grape seed oil by addition of grape seed extract. J. Korean Soc. Food Sci. Nut. 44, 1813-1818. https://doi.org/10.3746/ jkfn.2015.44.12.1813

Jeleń HH, Obuchowska M, Zawirska-Wojtasiak R, Waşowicz E. 2000. Headspace solid-phase microextraction use for the characterization of volatile compounds in vegetable oils of different sensory quality. J. Agric. Food Chem. 48, 23602367. https://doi.org/10.1021/jf991095v

Kasote DM, Badhe YS, Hegde MV. 2013. Effect of mechanical press oil extraction processing on quality of linseed oil. Ind. Crops Prod. 42, 10-13. https://doi.org/10.1016/j. indcrop.2012.05.015

Kiralan M, Özkan G, Bayrak A, Ramadan MF. 2014. Physicochemical properties and stability of black cumin (Nigella sativa) seed oil as affected by different extraction methods. Ind. Crops Prod. 57, 52-58. https://doi. org/10.1016/j.indcrop.2014.03.026

Kiralan M, Ramadan MF. 2016. Volatile oxidation compounds and stability of safflower, sesame and canola cold-pressed oils as affected by thermal and microwave treatments. J. Oleo Sci. 65, 825-833. https://doi.org/10.5650/jos. ess 16075

Kiralan M. 2014. Changes in volatile compounds of black cumin (Nigella Sativa L.) seed oil during thermal oxidation. International J. Food Prop. 17, 1482-1489. https://doi. org/10.1080/10942912.2012.723231

Kiralan M, Çalik G, Kiralan S, Ramadan MF. 2018. Monitoring stability and volatile oxidation compounds of coldpressedflax seed, grape seed and black cumin seed oils upon photo-oxidation. J. Food Measur. Charact. 12, 616621. https://doi.org/10.1007/s11694-017-9674-3 
Kiralan M, Ulaş M, Özaydin AG, Özdemir N, Özkan G, Bayrak A, Ramadan MF. 2017. Blends of cold pressed black cumin oil and sunflower oil with improved stability: A study based on changes in the levels of volatiles, tocopherols and thymoquinone during accelerated oxidation conditions. J. Food Biochem. 41, e12272. https://doi.org/10.1111/ jfbc. 12272

Koski A, Psomiadou E, Tsimidou M, Hopia A, Kefalas P, Wähälä K. Heinonen M. 2002. Oxidative stability and minor constituents of virgin olive oil and cold-pressed rapeseed oil. Eur. Food Res. Tech. 214, 294-298. https://doi. org/10.1007/s00217-001-0479-5

Krist S, Stuebiger G, Bail S, Unterweger H. 2006. Analysis of volatile compounds and triacylglycerol composition of fatty seed oil gained from flax and false flax. Eur. J. Lipid Sci. Tech. 108, 48-60. https://doi.org/10.1002/ ejlt.200500267

Lutterodt H, Luther M, Slavin M, Yin J-J, Parry J, Gao J-M, Yu L. 2010. Fatty acid profile, thymoquinone content, oxidative stability, and antioxidant properties of cold-pressed black cumin seed oils. LWT-Food Sci. Tech. 43, 1409-1413. https://doi.org/10.1016/j.lwt.2010.04.009

Lutterodt H, Slavin M, Whent M, Turner E, Yu L. 2011. Fatty acid composition, oxidative stability, antioxidant and antiproliferative properties of selected cold-pressed grape seed oils and flours. Food Chem. 128, 391-399. https://doi. org/10.1016/j.foodchem.2011.03.040

Matthäus B, Brühl L. 2003. Quality of cold-pressed edible rapeseed oil in Germany. Food/Nahrung 47, 413-419. https:// doi.org/10.1002/food.200390092

Parker TD, Adams DA, Zhou K, Harris M, Yu L. 2003. Fatty acid composition and oxidative stability of cold-pressed edible seed oils. J. Food Sci. 68, 1240-1243. https://doi. org/10.1111/j.1365-2621.2003.tb09632.x

Parry J, Su L, Luther M, Zhou K, Yurawecz MP, Whittaker P, Yu L. 2005. Fatty acid composition and antioxidant properties of cold-pressed marionberry, boysenberry, ted raspberry, and blueberry seed oils. J. Agric. Food Chem. 53, 566-573. https://doi.org/10.1021/jf048615t

Porto Cda, Porretto E, Decorti D. 2013. Comparison of ultrasound-assisted extraction with conventional extraction methods of oil and polyphenols from grape (Vitis vinifera L.) seeds. Ultrasonics Sonochem. 20, 1076-1080. https:// doi.org/10.1016/j.ultsonch.2012.12.002

Prescha A, Grajzer M, Dedyk M, Grajeta H. 2014. The antioxidant activity and oxidative stability of cold-pressed oils. $J$. Am. Oil Chem. Soc. 91, 1291-1301. https://doi.org/10.1007/ s11746-014-2479-1

Raczyk M, Popis E, Kruszewski B, Ratusz K, Rudzińska M. 2016. Physicochemical quality and oxidative stability of linseed (Linum usitatissimum) and camelina (Camelinasativa) coldpressed oils from retail outlets. Eur. J. Lipid Sci. Technol. 118, 834-839. https://doi.org/10.1002/ejlt.201500064

Ramadan MF. 2007. Nutritional value, functional properties and nutraceutical applications of black cumin (Nigella sativa L.) oilseeds: An overview. Int. J. Food Sci. Tech. 42, 12081218. https://doi.org/10.1111/j.1365-2621.2006.01417. x

Ramadan MF. 2013. Healthy blends of high linoleic sunflower oil with selected cold pressed oils: Functionality, stability and antioxidative characteristics. Ind. Crops Prod. 43, 65-72. https://doi.org/10.1016/j.indcrop.2012.07.013

Ramadan MF, Mörsel J-T. 2004. Oxidative stability of black cumin (Nigella sativa L.), coriander (Coriandrum sativum L.) and niger (Guizotia abyssinica Cass.) crude seed oils upon stripping. Eur. J. Lipid Sci. Tech. 106, 35-43. https:// doi.org/10.1002/ejlt.200300895

Ramadan MF, Asker MMS, Tadros M. 2012. Antiradical and antimicrobial properties of cold-pressed black cumin and cumin oils. Eur. Food Res. Tech. 234, 833-844. https://doi. org/10.1007/s00217-012-1696-9

Rudzińska M, Hassanein MMM, Abdel-Razek AG, Ratusz K, Siger A. 2016. Blends of rapeseed oil with black cumin and rice bran oils for increasing the oxidative stability. $J$. Food Sci. Tech. 53, 1055-1062. https://doi.org/10.1007/ s13197-015-2140-5

Siger A, Nogala-Kalucka M, Lampart-Szczapa E. 2008. The content and antioxidant activity of phenolic compounds in cold-pressed plant oils. J. Food Lipids 15, 137-149. https:// doi.org/10.1111/j.1745-4522.2007.00107.x

Snyder JM, Frankel EN, Selke E. 1985. Capillary gas chromatographic analyses of headspace volatiles from vegetable oils. J. Am. Oil Chem. Soc. 62, 1675. https://doi.org/10.1007/ BF02541664

Snyder JM, Frankel EN, Selke E, Warner K. 1988. Comparison of gas chromatographic methods for volatile lipid oxidation compounds in soybean oil. J. Am. Oil Chem. Soc. 65, 1617-1620. https://doi.org/10.1007/BF02912565

Takeyama E, Fukushima M. 2013. Physicochemical properties of Plukenetia volubilis L. seeds and oxidative stability of cold-pressed oil (green nut oil). Food Sci. Tech. Res. 19, 875-882. https://doi.org/10.3136/fstr.19.875

Tańska M, Roszkowska B, Skrajda M, Dąbrowski G. 2016. Commercial cold pressed flaxseed oils quality and oxidative stability at the beginning and the end of their shelf life. $J$. Oleo Sci. 65, 111-121. https://doi.org/10.5650/jos.ess 15243

Teh SS, Birch J. 2013. Physicochemical and quality characteristics of cold-pressed hemp, flax and canola seed oils. $J$. Food Comp. Anal. 30, 26-31. https://doi.org/10.1016/j. jfca.2013.01.004

Tuberoso CIG, Kowalczyk A, Sarritzu E, Cabras P. 2007. Determination of antioxidant compounds and antioxidant activity in commercial oilseeds for food use. Food Chem. 103, 1494-1501. https://doi.org/10.1016/j.foodchem.2006.08.014

Van Hoed V, Depaemelaere G, Ayala JV, Santiwattana P, Verhe R, De Greyt W. 2006. Influence of chemical refining on the major and minor components of rice brain oil. $J$. Am. Oil Chem. Soc. 83, 315-321. https://doi.org/10.1007/ s11746-006-1206-y

Vujasinovic V, Djilas S, Dimic E, Romanic R, Takaci A. 2010. Shelf Life of Cold-Pressed Pumpkin (Cucurbita pepo L.) Seed Oil Obtained with a Screw Press. J. Am. Oil Chem. Soc. 87, 1497-1505. https://doi.org/10.1007/s11746-010-1630-x

Wei CQ, Liu WY, Xi WP, Cao D, Zhang HJ, Ding M, Chen L, Xu YY, Huang KX. 2015. Comparison of volatile compounds of hot-pressed, cold-pressed and solvent-extracted flaxseed oils analyzed by SPME-GC/MS combined with electronic nose: Major volatiles can be used as markers to distinguish differently processed oils. Eur. J. Lipid Sci. Tech. 117, 320-330. https://doi.org/10.1002/ejlt.201400244

Wei C, Xi W, Nie X, Liu W, Wang Q, Yang B, Cao D. 2013. Aroma characterization of flaxseed oils using headspace solid-phase micro extraction and gas chromatographyolfactometry. Eur. J. Lipid Sci. Tech. 115, 1032-1042. https://doi.org/10.1002/ejlt.201200397

Wen X, Zhu M, Hu R, Zhao J, Chen Z, Li J, Ni Y 2016. Characterisation of seed oils from different grape cultivars grown in China. J. Food Sci. Tech. 53, 3129-3136. https://doi.org/10.1007/s13197-016-2286-9

Wroniak M, Florowska A, Rekas A. 2016. Effect of oil flushing with nitrogen on the quality and oxidative stability of coldpressed rapeseed and sunflower oils. Acta Sci. Polo. Tech. Alim 15, 79-87. https://doi.org/10.17306/J.AFS. 2016.1.8

Yu LL, Zhou KK, Parry J. 2005. Antioxidant properties of coldpressed black caraway, carrot, cranberry, and hemp seed oils. Food Chem. 91, 723-729. https://doi.org/10.1016/j. foodchem.2004.06.044 